\title{
Optimum Sizing and Economic Analysis of Standalone PV System with a Small Size Grinding Mill
}

\author{
Leonard Akana Nguimdo ${ }^{1 *}$, Leon Tientcheu Tassi ${ }^{2}$ \\ ${ }^{1}$ Department of Electrical and Electronic Engineering, Faculty of Engineering and Technology, University of Buea, Buea, Cameroon \\ ${ }^{2}$ Environmental Energy Technologies Laboratory (EETL), Faculty of Sciences, University of Yaoundé 1, Yaoundé, Cameroon \\ Email: *languimdo@yahoo.fr
}

How to cite this paper: Nguimdo, L.A. and Tassi, L.T. (2020) Optimum Sizing and Economic Analysis of Standalone PV System with a Small Size Grinding Mill. Energy and Power Engineering, 12, 432-444. https://doi.org/10.4236/epe.2020.127026

Received: May 20, 2020

Accepted: July 28, 2020

Published: July 31, 2020

Copyright $\odot 2020$ by author(s) and Scientific Research Publishing Inc. This work is licensed under the Creative Commons Attribution International License (CC BY 4.0).

http://creativecommons.org/licenses/by/4.0/ (c) (i) Open Access

\begin{abstract}
This work presents the results of the characterization of a standalone photovoltaic system for the electrification of a household located in rural area in the western region of Cameroon: Nziih-Bafou in Dschang $\left(5.35^{\circ} \mathrm{N}, 10.05^{\circ} \mathrm{E}\right.$ and $1900 \mathrm{~m}$ ). In order to cope with the maintenance charges and reduce the investment cost, a small mill was added to the appliances of the household for income generation. The assessment of the energy demand was made by taking into account the reactive energy due to the heavy consumption of energy by the mill's motor, especially during ignition. The sizing of all the system's components was carried out with the prospect of determining an optimum design in accordance with daily electricity demand, site irradiance profile and climatic conditions. In this context, tilt angles applicable to the PV structure and that allow to receive the maximum irradiance as a function of the periods of the year were determined using the Hay model. This approach provides the system with incident irradiance greater than or at the limit equal to that received by a horizontal surface on the same site compared to the case of a single tilt angle where the irradiance on the inclined plane is often lower than that on the horizontal. The economic analysis of the PV system showed an initial cost of $\$ 4448$ and the Life Cost Cycle amounted to $\$ 24,495$. This amount corresponds to a present cost per kilowatt hour of $\$ 0.44$. The Net Present Value (NPV) of the project (\$7793) over its lifetime (20 years) shows a payback period of less than 4 years.
\end{abstract}

\section{Keywords}

Standalone Photovoltaic System, Optimization, Hay Model, Reactive Energy, Life Cycle Cost, Net Present Value 


\section{Introduction}

Solar energy considered to be inexhaustible with regard to its potential compared to the energy needs of humanity varies according to the geographical location, the position of the sun, the orientation and the inclination of the collector. In Africa, this truly abundant energy is proving to be a major alternative to increasing demand due to gradual modernization of industrial processes and especially the growing population [1]. Although access has been slowly rising, more than 600 million people in Africa live without electricity, including more than 80 percent of those residing in rural areas [2]. With a rate of access to electricity of barely $21 \%$ in rural areas in 2017 [3], Cameroon is struggling to meet the electricity needs of its households. In addition, problems such as the obsolescence of energy transport equipments often causing load shedding, numerous complaints about billing and quality of service, slow interventions and many other drawbacks punctuate this low access rate.

Faced with this situation which seems to be common in many African countries [4], researchers are increasingly proposing the decentralized electrification solution on isolated sites and in rural areas in particular using the photovoltaic (PV) technology. In fact, Stojanovski et al. [5] through a survey that tracked approximately 500 early adopters of solar home systems (SHS) in two off-grid markets in Africa found that SHS were associated with large reductions in the use of kerosene and to a lesser extent, the use of small disposable batteries also decreased. In order to guarantee stable and accessible energy for the populations, Sakiliba et al. [6] proposed in Gambia a fixed tilt angle domestic PV system with a cost price per kWh lower than the unit price of electricity in the country. However, such a generator would not have the capacity to produce using the maximum radiation potential throughout the year. Kumar et al. [7] in view to improve the performance of $\mathrm{PV}$ systems maximized the incident energy received by solar modules by using variable optimum tilt angles according to the seasons of the year. One of the most important aspects of the standalone PV systems besides its reliability [8] [9] is the search for a good compromise between energy needs and the capacity to bear the installation cost which is high compared to the financial means of the populations in rural areas.

The present work in order to promote access to electricity studies the optimum PV sizing for a rural household in Nziih-Bafou village in the West region of Cameroon. This site was chosen for the strong economic capacities of the area which is a real commercial hub where several income-generating activities are developed. However, although connected to electrical power network, people face frequent power outage that causes significant losses in their activities. Irradiance on horizontal plane is also important with an annual average of 5.45 $\mathrm{kWh} / \mathrm{m}^{2} /$ day [10]. The peculiarity of the household taken into account here is to be equipped with a food grinding mill because agriculture is the primary activity in the area. The main objective of this paper is to design for this household an autonomous, efficient PV system that can guarantee its energy independence 
while contributing to income generation. This sizing is done with an optimization perspective both in the selection of equipments, the inclination of panels as the choice of electrical topology to allow the proper functioning of the PV station and to ensure a reasonable payback time.

The rest of the paper is organized as follows. Section 2 discusses the site solar potential and the household energy demand. The methodology for optimal sizing is presented in Section 3. Section 4 deals with the economic and environmental analysis of the station. Finally, Section 5 presents the results and discusses their usefulness. The major findings of the study are summarized in Section 6.

\section{Solar Potential and Energy Demand of the Household}

Figure 1 shows the monthly profile of average solar irradiation at Nziih-Bafou site $\left(10^{\circ} 05^{\prime} \mathrm{N}, 5^{\circ} 35^{\prime} \mathrm{E}\right.$ and $\left.1900 \mathrm{~m}\right)$ for a period of one year. These values are derived from Photovoltaic Geographical Information System (PVGIS) for the year 2016. PVGIS is the official site of the European Union which provides access to data on solar irradiation on horizontal plane, ambient temperature and tools for performance assessment of photovoltaic systems. The satellite data used to estimate the solar radiation are obtained from METEOSAT satellites covering Europe, Africa and most of Asia. The site produces an image per hour for a given station from January to December, which makes it possible to generate averages on a desired time scale (PVGIS, 2020). Figure 1 also compares these data to those received in the same locality by a flat inclined surface with tilt angle $\beta$ equals to the latitude of the site $\left(\beta=5^{\circ} 35^{\prime}\right)$.

It can be observed that the single tilt angle is not always appropriate because there are periods of the year where the irradiance on the inclined plane is less than the horizontal as demonstrated by Akana and Kum [11].

The average household which is used in this study was described following a survey based on Simple Random Sampling in the locality and it is therefore equipped with appliances that are generally present in the area. Table 1 summarizes these devices, their powers and the operating time for a day. In addition, the household has a grinding mill which consumes significant reactive energy,

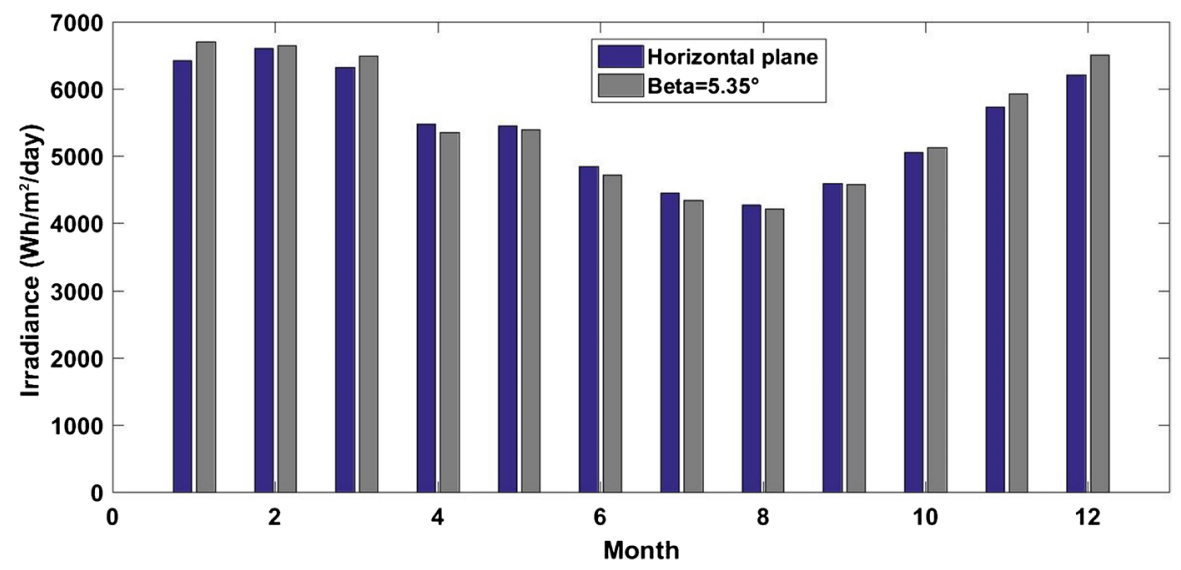

Figure 1. Sunshine on a horizontal plane (PVGIS, 2020) and for $\beta=5^{\circ} 35^{\prime}$. 
Table 1. Daily power demand of the household.

\begin{tabular}{cccccccc}
\hline $\begin{array}{c}\text { Electrical } \\
\text { Load }\end{array}$ & $\begin{array}{c}\mathbf{N}^{\bullet} \text { of } \\
\text { Units }\end{array}$ & $\begin{array}{c}\text { Operating } \\
\text { hours } \\
\text { per day }\end{array}$ & $\begin{array}{c}\text { Active } \\
\text { power } \\
(\mathbf{W})\end{array}$ & $\begin{array}{c}\text { Power } \\
\text { factor } \\
(\cos \varphi)\end{array}$ & $\begin{array}{c}\text { Reactive } \\
\text { power } \\
\text { (VAR) }\end{array}$ & $\begin{array}{c}\text { Apparent } \\
\text { power } \\
\text { (VA) }\end{array}$ & $\begin{array}{c}\text { Energy } \\
\text { per day } \\
(\text { VAh/j) }\end{array}$ \\
\hline TV & 1 & $\mathbf{5}$ & 100 & 0.8 & 75 & 125 & 625 \\
TV Decoder & 1 & 5 & 17 & 0.95 & 5.58 & 17.89 & 89.45 \\
LED Lamps & 7 & 7 & 70 & 0.95 & 23 & 73.68 & 515.76 \\
Refrigerator & 1 & 16 & 150 & 0.8 & 112.5 & 187.5 & 3000 \\
HiFi & 1 & 4 & 35 & 0.8 & 26.25 & 43.75 & 175 \\
Iron & 1 & 0.5 & 1500 & 1 & 0 & 1500 & 750 \\
Phone Charger & 4 & 5 & 20 & 0.95 & 6.57 & 21.05 & 105.25 \\
Mill & 1 & 3 & 750 & 0.8 & 562.5 & 937.5 & 2812.5 \\
Laptop & 1 & 2 & 65 & 0.8 & 48.75 & 81.25 & 162.5 \\
& & & Total & & & & 8235.46 \\
\hline
\end{tabular}

Table 2. Characteristics of the mill motor.

\begin{tabular}{ccccccc}
\hline Type & Voltage & $\begin{array}{c}\text { Rotations } \\
\text { per minute }\end{array}$ & Power & $\begin{array}{c}\text { Starting } \\
\text { Current }\end{array}$ & $\begin{array}{c}\text { Duty } \\
\text { Current }\end{array}$ & Frequency \\
\hline ML 802-4 & $220 \mathrm{~V}$ & 1410 & $750 \mathrm{~W}$ & $30 \mathrm{~A}$ & $4.75 \mathrm{~A}$ & $50 \mathrm{~Hz}$ \\
\hline
\end{tabular}

especially during ignition. Daily needs are then evaluated and considered constant throughout the year.

The characteristics of the mill's motor are as shown in Table 2.

\section{Design Optimization}

In order to guarantee optimal operation of the station, several factors are taken into account in the design.

\subsection{Optimization through Recoverable Solar Energy}

The position of the photovoltaic modules relative to the sun directly influences their energy production. It is therefore very important to appropriately install the panels so as to use them to the maximum of their possibilities. In this context, knowledge of the solar radiation received by an inclined surface is necessary for most applications concerning ground-based solar systems. Here we use Hay's anisotropic model [12] and evaluate the irradiation on a monthly time scale according to the method described by Akana and Kum [11] as

$$
G_{\beta}=G_{b} \frac{\cos \theta_{i}}{\cos \theta_{z}}+\frac{1}{2} \rho G(1-\cos \beta)+G_{d}\left[\frac{\cos \theta_{i}}{\cos \theta_{z}} \frac{G_{b}}{G_{0}}+0.5\left(1-\frac{G_{b}}{G_{0}}\right)(1+\cos \beta)\right]
$$

where $G_{b}$ and $G_{d}$ are respectively direct and diffuse radiations on a horizontal surface $\left(\mathrm{W} / \mathrm{m}^{2}\right) . \rho$ is the surface albedo, $G$ the total irradiance on horizontal plane $\left(\mathrm{W} / \mathrm{m}^{2}\right), G_{\beta}$ the total irradiance on tilted surface and $G_{0}$ the solar 
constant.

With

$$
\begin{gathered}
\cos \theta_{i}=\cos \beta \cdot \cos \theta_{z}+\sin \beta \cdot \sin \theta_{z} \cdot \cos A \\
\cos \theta_{z}=\cos \theta \sin \varphi+\cos \delta \cos \varphi \cos \omega
\end{gathered}
$$

where $\theta_{z}$ is the solar zenithal angle, $\delta$ the declination, $\varphi$ the latitude of the site, $\omega$ the hourly angle and $A$ the azimuth.

\subsection{Sizing and Design Technology}

The optimal and harmonious functioning of a photovoltaic installation requires efficient sizing and a judicious choice of the essential elements (Figure 3 ) that make up the generator.

\subsubsection{Photovoltaic Field}

The peak power $\left(P_{p}\right)$ of the PV field expressed in Watt peak $\left(W_{p}\right)$ is by definition the power it delivers under a solar radiation of $1000 \mathrm{~W} / \mathrm{m}^{2}$. It strongly depends on the irradiation of the site and is obtained from the following equation

$$
P_{p}=\frac{E_{\text {Demand }} \times 1\left(\mathrm{~kW} / \mathrm{m}^{2}\right)}{P R I_{r}}
$$

$E_{\text {Demand }}$ is the daily energy demand of the household (kWh/day) and $I_{r}$ the average daily irradiation $\left(\mathrm{kWh} / \mathrm{m}^{2} /\right.$ day) during the worst month.

$P R$ is the de performance ratio. In the case of this installation, the modules are to be placed close to the ground to allow good ventilation of the photovoltaic field. In addition, the charge regulator is MPPT technology. We will then use $P R=0.75$.

The number of panels in series $\left(N_{P S}\right)$ is calculated by

$$
N_{P S}=\frac{V_{G}}{V_{P}}
$$

where $V_{G}$ is the voltage across the photovoltaic generator, $V_{P}$ the rated voltage of PV panel.

Similarly, the number of branches in parallel $\left(N_{P P}\right)$ is calculated as follows

$$
N_{P P}=\frac{P_{p}}{P_{m}} \times \frac{1}{N_{P S}}
$$

where $P_{m}$ is the peak power of PV module $\left(W_{p}\right)$.

The total number $N$ of panels to be installed is given by

$$
N=N_{P S} \times N_{P P}
$$

We deduce the total surface $A_{T}$ occupied by the panels

$$
A_{T}=A_{P} \times N
$$

where $A_{P}$ is the area of a PV panel and the energy produced by the PV field per day

$$
E_{\text {daily }}=P_{p} \times N_{p}
$$




$$
E_{\text {daily }}=P_{p} \times N_{p}
$$

where $N_{p}$ is the daily duration of Peak sunshine (hours).

\subsubsection{Sizing of the Battery Bank}

The lead-acid battery is the most common form of electrical energy storage due to an established manufacturing base, therefore a relatively low cost and wide availability. The storage capacity $C_{B}(\mathrm{~A} \cdot \mathrm{h})$ of the battery bank is given by

$$
C_{B}=\frac{E_{\text {Demand }} \times n}{\eta_{b a t} \eta_{i} \eta_{q} \times \mathrm{DOD} \times V}
$$

With $n$ the number of days of autonomy, DOD the maximum depth of discharge (in \%). $\eta_{b a t}, \eta_{i}$ and $\eta_{q}$ are the efficiencies of the battery, the inverter and the charge controller respectively. $V$ is Battery bank voltage (Volts).

The number of batteries in series is determined by

$$
B_{s}=\frac{\text { PV Field Voltage }}{\text { Battery Rated Voltage }}
$$

And in parallel we have

$$
B_{p}=\frac{\text { Total Storage Capacity } C_{B}(\mathrm{~A} \cdot \mathrm{h})}{\text { Battery Rated Capacity }(\mathrm{A} \cdot \mathrm{h})}
$$

We deduce the total number of batteries for the system by

$$
B=B_{p} \times B_{s}
$$

\subsubsection{Charge Controller and Inverter}

The nominal input voltage of the charge controller is equal to that of the photovoltaic field which in this case has been taken equal to $48 \mathrm{~V}$. The input current $\left(I_{e}\right)$ is the maximum duty current that the modules are capable of delivering at a given moment. This current is obtained by the product of the short-circuit current of a module (ICC) by the number of branches of PV modules in parallel $\left(N_{P P}\right)$. This product for safety reasons is corrected by a safety factor of 1.25 [13].

$$
1.25 I c c_{\max } N_{p p} \leq I_{e}
$$

As for the inverter, it must be sized so that its nominal power covers the sum of the powers of all users. Figure 2 shows the configuration of the standalone PV system considered in this study.

\section{Economic and Environnemental Analysis}

\subsection{Project Assessment}

The economic method applied here is the Life Cycle Cost (LCC). The LCC of a system is the present monetary value of all the acquisition, operation and maintenance expenses of the system over its lifetime [14]. For our station, these costs also take into account the renewal of used equipment before the lifetime. This is the case of the batteries which are replaced every five years, which suggests 3 additive lots that will have to be acquired during the life of the project. The present 


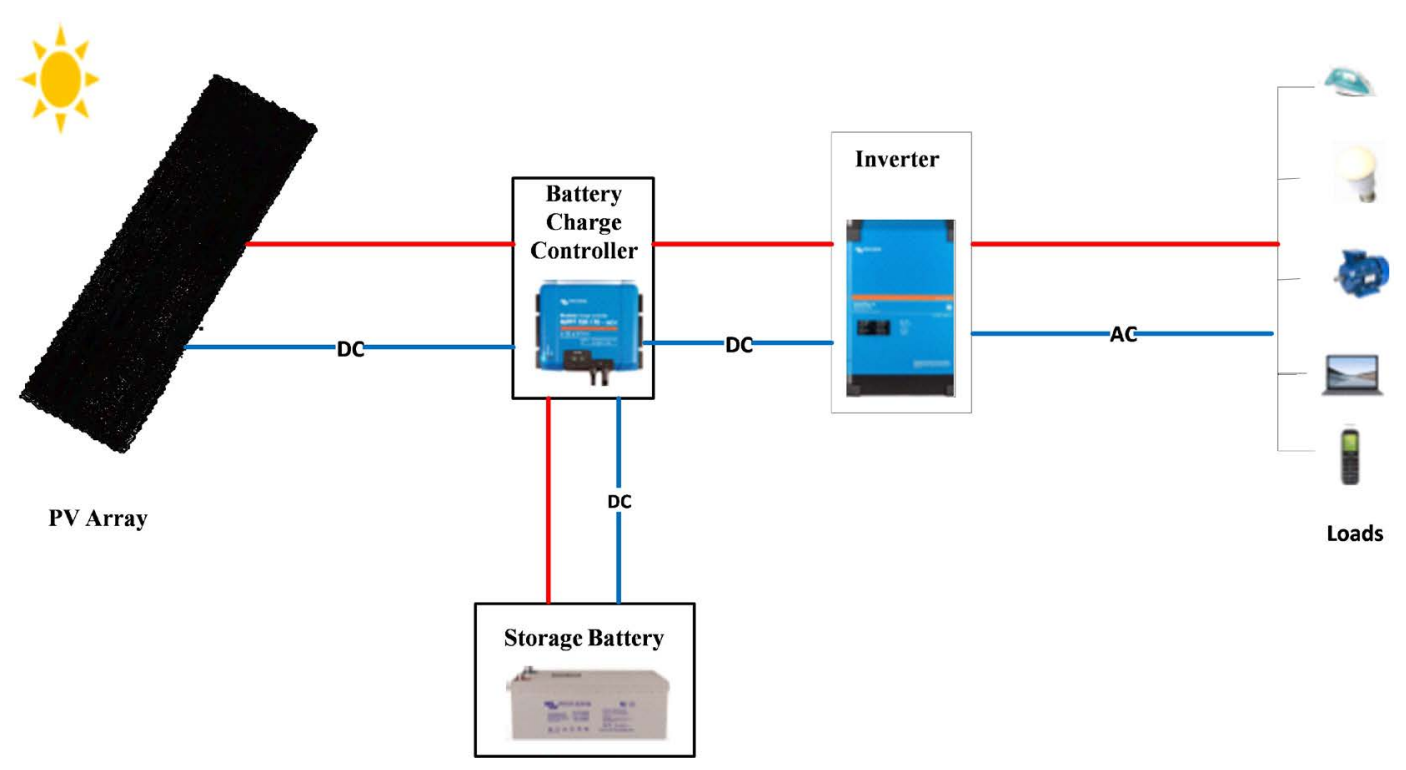

Figure 2. Proposed design for the PV system.

value ( $C_{X n}$ ) of the batch of equipment $X$ of order $n$ acquired after $k$ years is given taking into account the inflation $(i)$ and depreciation $(t)$ rates as

$$
C_{X n}=C_{X}[(1+i) /(1+t)]^{k}
$$

where $X$ designate the equipment and $C_{X}$ its initial purchase price.

The LCC is then given by the following expression

$$
\mathrm{LCC}=C_{G P V}+C_{b a t}+C_{i n v}+C_{c o n t}+C_{o p}+C_{i n s}
$$

where $C_{P V G}$ is the cost of the $\mathrm{PV}$ generator and its accessories. $C_{i n v}, C_{c o n t}, C_{b a t}, C_{o p}$ and $C_{i n s}$ the respective costs of the inverter, regulator, battery, operation and installation.

The LCC reduced to the annual scale (ALCC) is described by

$$
\mathrm{ALCC}=\operatorname{LCC}\left\{\left[1-\left(\frac{1+i}{1+t}\right)\right] /\left[1-\left(\frac{1+i}{1+t}\right)^{N}\right]\right\}
$$

We then deduct the present total cost of a kWh by

$$
C_{k W h}=\frac{\mathrm{ALCC}}{365 E_{\text {Demand }}}
$$

The Net Present Value (NPV) is the profitability indicator of a project. The investment is profitable if the NPV is positive and unprofitable otherwise. NPV is given by the following equation

$$
\mathrm{NPV}=-I_{t o t}+\sum_{k=1}^{N} G_{k} \times(1+t)^{-k}
$$

where $I_{t o t}$ is the initial investment, $G_{k}$ the cash flow of year $k, N$ the estimated life of the project and $t$ the depreciation rate of the investment. In our case we will take this rate equal to $10 \%$ in agreement with Derbie Gont [15]. Assuming constant revenues and expenses, the cash flow does not vary throughout the duration of the project, we then have 


$$
\mathrm{NPV}=-I_{t o t}+\frac{G}{K_{a}(N, t)}
$$

where, $G$ is the constant value of cash flow and $K_{a}(N, t)=\frac{t}{1-(1+t)^{-N}}$

The updated payback time $(T)$ determines when the project becomes profitable. It therefore corresponds to the moment where the NPV is zero and is deduced from the equation

$$
-I_{t o t}+\sum_{i=0}^{T} \frac{G}{(1+t)^{T R A}}=0
$$

\subsection{Environmental Analysis}

The main indicator of the green nature of a renewable energy installation is the amount of $\mathrm{CO}_{2}$ avoided. For the autonomous photovoltaic system, this quantity is given by

$$
Q_{\mathrm{CO}_{2}}=E_{p} N Q_{0}
$$

where, $E_{p}$ is the energy produced per year, $N$ the lifespan of the project (20 years) and $Q_{0}$ the greenhouse gas emission factor of the PV generator. This factor varies depending on where the solar equipment is manufactured and also where it is used. The equipment used here is manufactured in China. Thus, the value of $Q_{0}$ for Ndziih-Bafou (Cameroon) was evaluated to be $0.094 \mathrm{~kg} / \mathrm{kWh}$.

\section{Results and Discussion}

\subsection{Recoverable Solar Energy}

Figure 3 shows the household load profile. There are two peaks of 1178.4 VAh between 8 am-10 am and 1 pm-13 pm corresponding to the operating hours of the mill. This profile is assumed to be constant throughout the lifespan of the

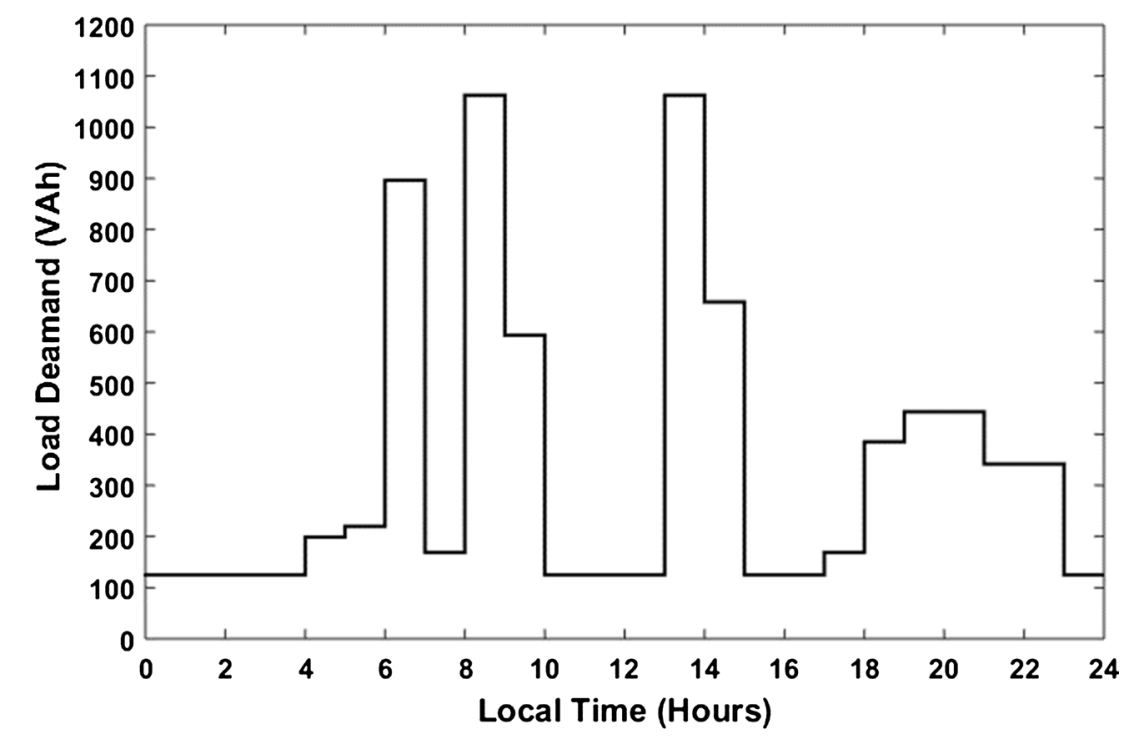

Figure 3. Load profile of the household. 
station and must be satisfied regardless of the fact that sunshine is favorable or not at a given period of the year.

This requires an adequate orientation allowing the panels to permanently receive the maximum irradiance. Figure 4 shows the average monthly availability of daily irradiance at Ndziih-Bafou for panels tilt angle varying from 0 to $90^{\circ}$.

It can be seen that an optimum angle $\beta_{\text {opt }}$ for which the incident radiation is at its peak exists for each month of the year. For five consecutive months, this peak corresponds to a layout of the panels along the horizontal $\left(\beta_{\text {opt }}=0\right.$ ). However, the radiation received by the panels during these periods is greater than that it would receive if the tilt were at a single angle (Figure 1). For the other months of the year, there was a significant increase in incident radiation. Table 3 summarizes for each month the optimal tilt angle and the corresponding irradiance. It also compares the optimized irradiance to that obtained for a fixed tilt. The installation will then be mounted on a frame having a crank allowing manual implementation of the optimal monthly tilt without any additional financial implications. This result contrasts with that of Khaled and Doraid (2012), Derbie Gont (2019) who considered a fixed angle all year round.

\subsection{Sizingthe PV Generator}

From the daily consumption (8235.46 VAh) and the solar irradiance data, we can calculate using (4) the peak power $P_{p}$ necessary for the proper functioning of the installation.
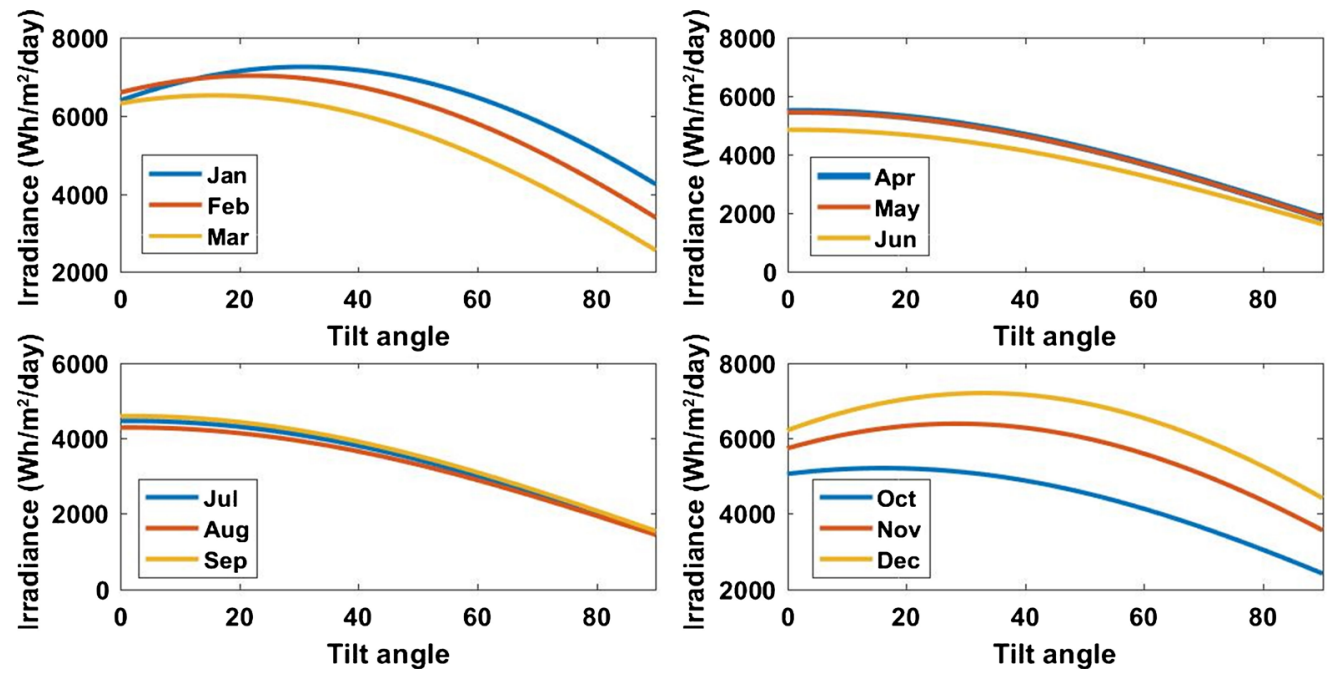

Figure 4. Average monthly availability of daily irradiance at Ndziih-Bafou.

Table 3. Monthly values of the optimal tilt angle as well as the irradiance.

\begin{tabular}{|c|c|c|c|c|c|c|c|c|c|c|c|c|}
\hline Month & Jan & Feb & Mar & April & May & Jun & Jul & Aug & Sept & Oct & Nov & Dec \\
\hline$\beta_{\text {opt }}($ degree $)$ & 32 & 23 & 17 & 0 & 0 & 0 & 0 & 0 & 3 & 17 & 30 & 34 \\
\hline Optimum Irradiance $\left(\mathrm{kWh} / \mathrm{m}^{2} /\right.$ day $)$ & 7.25 & 7.03 & 6.52 & 5.48 & 5.45 & 4.85 & 4.45 & 4.28 & 4.58 & 5.20 & 6.38 & 7.19 \\
\hline Irradiance for unique $\beta\left(\mathrm{kWh} / \mathrm{m}^{2} /\right.$ day $)$ & 6.71 & 6.65 & 6.49 & 5.35 & 5.40 & 4.72 & 4.35 & 4.22 & 4.58 & 5.13 & 5.93 & 6.51 \\
\hline
\end{tabular}




$$
P_{p}=\frac{8235.46 \times 1}{4280 \times 0.75}=2.56 \mathrm{~kW}_{\mathrm{p}}
$$

The solar panels are monocrystalline of the type Felicity Solar (310 Wp, 36 V). According to (5), the number of panels in series is $N_{S}=\frac{48}{36}=1.33$ i.e. 2 panels in series.

The number of branches in parallel According to (6) is:

$$
N_{p}=\frac{2.56}{0.31 \times 2}=4.12 \text { i.e. } 5 \text { branches in parallel }
$$

It comes that the total number of panels to install is $N_{T}=10$ panels

The total surface that the panels will occupy is $A_{T}=10 \times 2=20 \mathrm{~m}^{2}$

To avoid that the panels are too close together, we will increase this total area by de $30 \%$ i.e. $A_{T}=26 \mathrm{~m}^{2}$.

Figure 5 presents the energy demand as a function of the PV field production and of the optimized irradiance during the whole year.

It can be seen that the PV field production covers the household energy demand all year round. During periods of strong sunshine, this production is well above demand.

\subsection{Sizing of Battery, Inverter and Regulator}

The batteries used are the GEL (150 Ah, $12 \mathrm{~V}$ ) type. They have an efficiency of $85 \%$ and a depth of discharge of $80 \%$. Given the sunshine in the region and the data in Figure 5, the autonomy of one day is chosen. So we have

$$
C_{B}=\frac{8235.46 \times 1}{0.85 \times 0.98 \times 0.94 \times 0.8 \times 48}=273.89 \mathrm{~A} \cdot \mathrm{h} \approx 274 \mathrm{~A} \cdot \mathrm{h}
$$

The number $B_{S}$ of batteries in series according to Equation (11) is $B_{S}=\frac{48}{12}=4$. In parallel we have $B_{p}=\frac{274}{150}=1.83 \approx 2$. The station will finally have 8 batteries in total.

The charge regulator capable of withstanding the short-circuit current of the PV generator while maintaining the voltage of the DC bus is the MPPT type. For

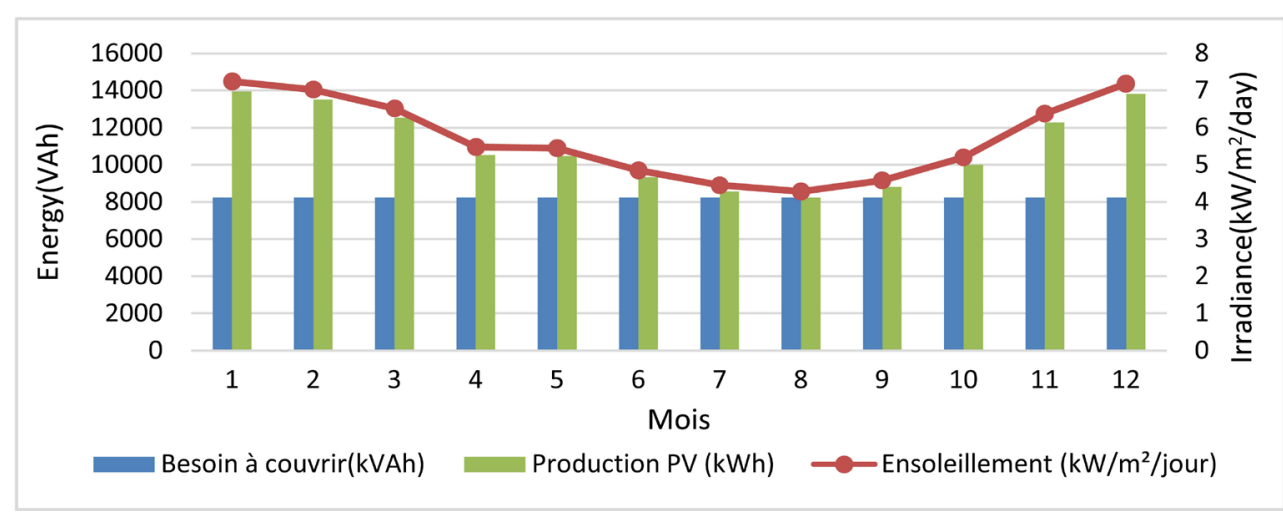

Figure 5. Comparing the Energy demand with the energy generated and the irradiance at Ndziih-Bafou. 
this study, we choose the MPPT $60 \mathrm{~A} / 48 \mathrm{~V}$ regulator with $60 \mathrm{~A}$ input current. As for the inverter, the sum of the nominal powers of the charging system is 2800 $\mathrm{VA}$. The input power of the inverter will therefore be equal to $3 \mathrm{kVA}$ (at least) with a DC voltage of $48 \mathrm{~V}$ and $50 \mathrm{~Hz}$ frequency.

\subsection{Economic and Environmental Applications}

Table 4 presents the estimated cost of the initial investment. The prices of the equipments are those applied on the local market and expressed in US dollars according to the exchange rate in force on January 1,2020 . The mill which operates 6 days a week, the seventh being devoted to maintenance, accumulates a total of approximately 313 days of operation per year. It produces 917 \$/year, from which the owner takes the manager's salary of $400 \$ / y e a r$, as well as the maintenance costs of the mill and the PV system which amounts to 267 \$/year. Thisannual expense (667 \$/year) represents $17.24 \%$ of the initial investment. Such an approach makes the project more profitable because part of the expenses is covered by the production of the system itself. The equipments will be replaced as follows: Regulators after 8 years, Inverter 11 years and 5 years for the batteries. The total energy consumption at constant yearly yield after 20 years is $60,120 \mathrm{kWh}$.

The LCC of the system for the lifetime of 20 years amounts to $\$ 24,495$. This value corresponds to an updated total cost per kWh of $\$ 0.44$. Figure 6 presents the NPV of the system over its operating time. This graph shows that the project becomes profitable between the $3^{\text {rd }}$ and $4^{\text {th }}$ year. Furthermore, the amount of $\mathrm{CO}_{2}$ that would be avoided by using the generator over 20 years is $5652 \mathrm{~kg}$.

\section{Conclusion}

This study dealing with optimal sizing describes both technically and economically the possibility for a household in Ndziih-Bafou to equip itself with a standalone PV station to solve the problem of energy stability. The economic study made it possible to determine the cost of carrying out this project which amounts to $\$ 4448$ with an updated cost of $\$ 0.44$ per $\mathrm{kWh}$ and a payback period between the $3^{\text {rd }}$ and $4^{\text {th }}$ years. More expensive than the national electricity company which offers a rate of $0.125 \$ / \mathrm{kWh}$ for monthly consumption less than or equal

Table 4. Estimated cost of initial investment.

\begin{tabular}{ccccc}
\hline Items & Model & Quantity & $\begin{array}{c}\text { Unit } \\
\text { Price (\$) }\end{array}$ & $\begin{array}{c}\text { Total } \\
\text { Price (\$) }\end{array}$ \\
\hline PV Modules & FL-M-310 (310 Wp; 36 V) & 10 & 160 & 1600 \\
Batteries & FL-G-150AH12V (150 Ah; 12 V) & 8 & 200 & 1600 \\
Controller & FL-SCCM-6048 MPPT 60 A/48V & 1 & 254 & 254 \\
Inverter & FL-IVPL3548-3500VA (3.5 kVA; 48 V) & 1 & 414 & 414 \\
Labor and accessories & 15\% of components cost & & 580 & 580 \\
\multicolumn{2}{c}{ Total cost of initial investment (\$) } & & & 4448 \\
\hline
\end{tabular}




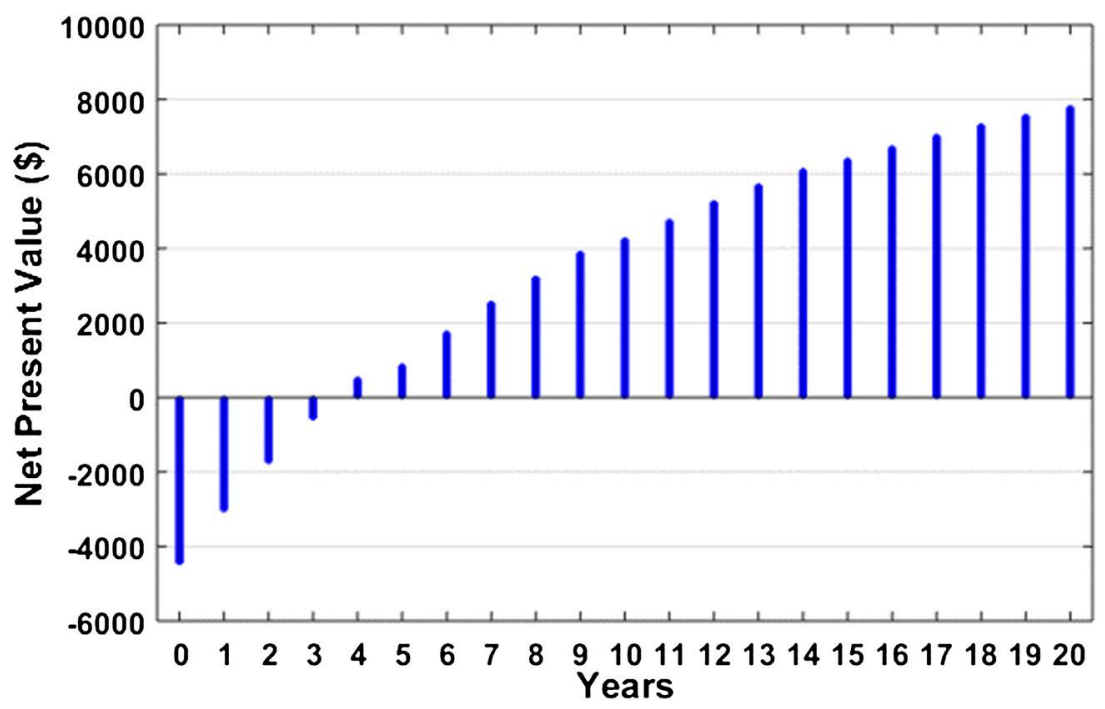

Figure 6. NPV of the PV system.

to $110 \mathrm{kWh}$, this solar generator is quite profitable over the life of the project and offers many advantages such as guarantee of permanent and stable energy and contribution to a cleaner world. The NPV over the lifetime of the system is \$7793. From an environmental standpoint, the result is quite interesting. This autonomous PV system would prevent $5652 \mathrm{~kg}$ of $\mathrm{CO}_{2}$ over 20 years. This study would represent a starting point solution for electrification problem in isolated rural areas in Cameroon and will contribute in the promotion of sustainable development in rural areas where sunshine is generally favorable for the production of electricity from solar energy.

\section{Conflicts of Interest}

The authors declare no conflicts of interest regarding the publication of this paper.

\section{References}

[1] Kruger, W. and Eberhard, A. (2018) Renewable Energy Auctions in Sub-Saharan Africa: Comparing the South African, Ugandan, and Zambian Programs. WIREs Energy and Environment, 7, e295. https://doi.org/10.1002/wene.295

[2] Blimpo, M.P. and Cosgrove-Davie, M. (2019) Electricity Access in Saharan Africa: Uptake, Reliability, and Complementary Factors for Economic Impact. A Copublication of the Agence Française de Développement and the World Bank. https://doi.org/10.1596/978-1-4648-1361-0

[3] Infrastructure Consortium for Africa Regional Power Status in African Power Pools, ICA, 120 p. http://www.icafrica.org/

[4] Quitzow, R., Roehrkasten, S., Jacobs, D., Bayer, B., Jamea, E.M., Waweru, Y. and Matschoss, P. (2016) The Future of Africa's Energy Supply. Potentials and Development Options for Renewable Energy, Institute for Advanced Sustainability Studies IASS, Potsdam.

[5] Stojanovski, O., Thurber, M. and Wolak, F. (2017) Rural Energy Access through Solar Home Systems: Use Patterns and Opportunities for Improvement, Energy for Sus- 
tainable Development. Energy for Sustainable Development, 37, 33-50. https://doi.org/10.1016/j.esd.2016.11.003

[6] Sakiliba, S. K., Hassan, A.S., Wu, J.Z. and Sanneh, E.S. and Ademi, S. (2015) Assessment of Stand-Alone Residential Solar Photovoltaic Application in Sub-Saharian Africa: A Case Study of Gambia. Journal of Renewable Energy, 2015, Article ID: 640327. https://doi.org/10.1155/2015/640327

[7] Kumar, A., Thakur, N.S., Makade, R. and Shivhare, M.K. (2011) Optimization of Tilt Angle for Photovoltaic Array, International Journal of Engineering Science and Technology, 3, 3153-3161.

[8] Benaventea, F., Lundblad, A., Campana, P.E., Zhang, Y., Cabrera, S. and Lindbergh, G. (2019) Photovoltaic/Battery System Sizing for Rural Electrification in Bolivia: Considering the Suppressed Demand Effect. Applied Energy, 235, 519-528. https://doi.org/10.1016/j.apenergy.2018.10.084

[9] Quiles, E.O., Roldán-Blay, C., Escrivá-Escrivá, G., and Roldán-Porta, C. (2020) Accurate Sizing of Residential Stand-Alone Photovoltaic Systems Considering System Reliability. Sustainability, 12, 1274. https://doi.org/10.3390/su12031274

[10] Photovoltaic Geographical Information System (PVGIS) Database for Africa, Hourly Solar Irradiation in Nziih-Bafou. http://www.pvgis.net/

[11] Akana Nguimdo, L. and Kum, C. (2020) Optimization and Sizing of a Stand-Alone Photovoltaic System and Assessment of Random Load Fluctuation on Power Supply. Energy and Power Engineering, 12, 28-43. https://doi.org/10.4236/epe.2020.121003

[12] Hay, J.E. (1979) Calculation of Monthly Mean Solar Radiation for Horizontal and Inclined Surfaces. Solar Energy, 23, 301-307. https://doi.org/10.1016/0038-092X(79)90123-3

[13] Belhaouas, N., Khechafi, S., Mehareb, F., Aseem, H., Bensalem, S. and Arab, A.H. (2019) Electrical Standalone PV System Sizing with Graphicuser Interface (GUI) Based on UTE C15-712-2 Guide. 2019 7th International Renewable and Sustainable Energy Conference (IRSEC), Agadir, Morocco, 27-30 November 2019, 1-5.

[14] Khaled, B. and Doraid, D. (2012) Optimal Configuration for Design of Stand-Alone PV System. Smart Grid and Renewable Energy, 3, 139-147. https://doi.org/10.4236/sgre.2012.32020

[15] Derbie Gont, S.(2019) Design of a Standalone Photovoltaic System for a Typical Household around Dessie City-Ethiopia. American Journal of Electrical and Electronic Engineering, 7, 1-7. 